\section{Global and Local Discourses on Climate Change: A Perspective from the Concept of Embeddedness}

Jailab Kumar Rai

\begin{abstract}
Climate change has been becoming a major order of business of all including researchers and academics. This is known that global, national and local organizations, institutions and even the individuals are partaking into the issues with their own perspectives and skills of negotiations. Despite the series of international efforts and attempts, there are also a series of national concerns, efforts and attempts in combating against the effects of global climate change. This paper is an attempt to draw on the overview of contexts and concerns of international communities for combating global climate change and its discursive influence in national policy discourses. Moreover, the paper attempts to assess the local socio-cultural discourses and dynamics of climate change in relation to global and national discourses. Finally the paper highlights on how global and local climate change knowledge networks and epistemic communities either from political processes or the socio-economic fabrics are interrelated and determinant to each other.
\end{abstract}

Keywords: climate change, discourses, embeddeness, dynamics, global, local

\section{Introduction}

Global climate change has become as increasing visible topic in public culture over the past few decades, and is likely to dominate environmental, political, and social agendas for some time to come (Peterson and Broad, 2009:70). We see that the global society is in the phase of relocating its development discourses focusing on the needs of global political negotiations to combat with the increasing effects of global climate change. It is becoming able to take wider attentions with series of events followed by political and other forms of negotiations. It is scientifically proved believed that no society can stop climate change, but efforts can be made to minimize vulnerability to the deleterious impact and enhance the resilience of social system and societal upheavals as a result of extreme climatic events. Hassan (2009: 61) seems to be optimistic with these events saying that it may provide an incentive to relocate, intensify food production, or reorganize political institutions governing labour, exploitation resources, distribution, consumption, and environmental impacts. Here, the expression of Stuckenberger ((2009) may be a part of knowledge in responding to the growing climate change risks. He said that climate change and its human dimension is clearly recognized as a global issue that requires interdisciplinary approach seeking to understand strategies that communicate greater awareness to a range of diverse audience. The government of Nepal also is becoming a part of this global discourse. It has official commitment to work jointly on the initiative for climate change responses through different means and mechanisms (GN/MoFSC, 2010). These all discourses are developed on the background of increasing warming in the globe. The available data show that the earth temperature near the earth surface rose by $0.74-0.18^{\circ}$ Celsius during $20^{\text {th }}$ century and scientists estimate that it could increase as much as $64^{\circ}$ Celsius on average during the $21^{\text {st }}$ century (IPCC, 2007a; Wigley, 1999). In this background context, this paper attempts to analyze on how a micro socio-economic dynamics and discourses occurring in a local setting is interrelated with national and international political dynamics of global climate change.

\section{Methods}

This study is based on two approaches: one is the analysis of international and national documents related to the efforts and actions against climate change issues; and another is the observation and understanding from a week long field-visit in Mustang district of the country in September 2009. In this visit, a team of 14 CA members affiliated with a Parliamentary Action Team on Environment, Climate Change and Disaster Risk Reduction (PAECD) have participated in the climate change 
impact study visit in this district. The visit team was coordinated by Forest Action Nepal. This team visited and observed a number of Village Development Committees (VDCs) viz Muktinath (second interaction and 50 participants), Kagbeni, Jomsom (third interaction and 150 participants), Marpha (first interaction and 150 participants), Tukche and Kobang. The agricultural productions, housing patterns, and other discrete events were observed. During the visit, formal and informal interactions with local people were also conducted. Along with informal individual interaction with local people, listening and questioning to participants in three interaction programs facilitated and organized by local communities and local organizations were important and interesting for enriching the understanding from local perspectives.

The aim of the visit was taking first hand information on climate change impacts in local environment and livelihoods in this district. The visit hence was focused on gathering an in-depth insights and knowledge of local people for informed policy decision on climate change in future policy dialogues including constitution drafting process and government programs. The study team have directly witnessed the multiple impacts of climate change in the region backed up by information obtained from direct interaction with the local people, who have long experiences and observations on the changing weather patterns, agricultural productions, and other forms of anecdotal in the locality.

\section{Climate Change: The Context of Global and Local Interface}

The concept 'climate change' has been decorous of involvement for academics, development practitioners, researchers, politicians and others these days. For Finan (2009: 175) it has begun to permit most level of human activity and interest, and it is now part of parcel of the public domain. The term 'climate change' refers to the contemporary phenomena of anthropogenic global climate change, as distinct from natural climate variability (Susan and Nuttall, 2009:35; Marino and Schweitzer, 2009: 209). It may not be just a temperature, but also includes factors such as humanity, precipitation, cloudiness, winds etc (Dessler and Parson, 2006: 47). The variations in climatic parameters is attributed directly or indirectly to human activities (ibid: quoted from Lange, 2005:365). It is increasing the risk of flooding, storms, deforestation, desertification, soil erosion, and sea level rise contributing to international and national migration with the experiences of privation, loss of homes, jobs, and the breakup of families and communities (Oliver-Smith, 2009: 132). Hence, the impact of climate change is not uniform across the globe, and considerable differences can be perceived between different regions, places and communities (UNFCCC, 1994; Hassan 2009, Peterson and Broad 2009, Roncoli et al, 2009; Schneider and Lane, 2006; Leichenko and O’Brien, 2006).

The potential risk of vulnerability to climate change is expected to be high in mountains and the coastal areas of the sea- the island countries (UNFCCC, 1994; Dessler and Parson, 2006). Dessler and Parson (2006:1) further view that 'climate change' does not just affect people directly, it also affects all other environmental and ecological processes, including many that we might not recognize as related to climate change. The risks of climate change for least developed countries like Nepal can hardly be exaggerated and communities, governments and other institutions have lot of functional challenges to minimize the adverse effects of climate change (GN/MoFSC, 2010). For this, developed countries are offering incentives to developing countries like Nepal for taking actions that reduce forest related carbon emissions for combating the risk of climate change (Conventions of the Parties-COP 12, 13, 14). This is with the aims of making forest conservation and management economically viable and financial incentives (GN/MoFSC, 2010).

Culture frames the way people perceive, understand, experience, and respond to key elements of the worlds which they live in (Roncoli et al, 2009: 87). This framing is grounded in system of meanings and relationships that mediate human engagements with natural phenomena and global political processes. Crate (2009:148) says that civil society and self advocacy (including 
anthropologists) are some where playing proactive roles $^{1}$ as communicators by seeking out the local, regional, and national channels through which local voices can affect any forms of policies. Here, the notion of the construction of social reality and the 'embeddedness approach' (McCay, 2009: 382-394), in understanding and analyzing individual human behaviors, their institutions, human-environment relation, micro-macro structural relations, and others, is important part of resolving the discrepancy between agency and structured based approaches. It means the understanding of the concept emphasizes the needs of understanding social networks (Swedberg and Granovetter, 1992, quoted in McCay, 2009: 381) patterned in the dynamics of human and institutional interactions. He further says that people in communities talk to each other and to outsiders about particular risks, and that is what creates their meaningful, action-prompting perceptions on the emerging risks.

Crate (2009:146-147) says that global climate change is caused by the multiple drivers of our global consumer culture, transforms symbolic and subsistence cultures, and will only be forestalled via a cultural transformation from degenerative to regenerative consumer behavior. The human agency and their adaptability in changing context is to develop their own sense of impact of climate change in human societies (Hasan, 2009: 44). The variation of the size, scale of organization, social differentiation, subsistence activities, productive strategies, ideologies, and worldviews play the important roles in this regard. The way how they are maintained, reproduced, and transformed as a result of the impact of day to day practices by individuals who are constrained by their perceptions, beliefs, norms, values and mind sets as cognitive schemata and are outcomes of their either positive or negative perceptions (ibid: quoted from Craik, 1972). He further says that there are short-term and long-term consequences of climate change and the current attempt at greening of politics of remedying the potential catastrophic consequences aim to remedy the shortsighted modus operandi of societies (ibid: 61).

1 Susan Crate in her article 'Gone the Bull of Winter' writes that indigenous groups are proactive in Canada, Greenland, and Alaska against the issues of global climate change.
It is said that when the particular community has access to information about how climate change is affecting their lives, often in tandem with seeing changes to their lands, then they act accordingly against the impacts in their life ways (Green, 2009: 225). Fiske (2009: 288) raises a question on action against climate change. He raises a question of how can global climate change policies be designed to work to benefit local communities in the developing world or work to their detriment. Here, Nuttall (2009: 308-309) argues that the adaptation to extreme climate events will be a measure of ability or inability of individual, household, and communities to make decisions that allow them to respond effectively and with a degree of autonomy. He further argues that it is challenge to understand climate change within a broader context of political processes and ambition, cultural specificity, and people's epistemological, social, cultural, economical and moral relationship with the environment. The arguments of Puntenney (2009:319-320) may be interconnected herewith. He says that upon closure examination of the issues surrounding climate change, we know by definition that the outcomes of international debates are the result of complex interactions of many factors, including sudden changes in the global environment or scientific understanding, macroeconomic trends, domestic and international political environments, and the presence or absence of effective leadership. Bohren (2009) based on the car culture in US also concluded that transformation in the ethos of individualism, personal freedom, and mobility away from reliance on the car as cultural challenge of technological and behavioral components of emission reduction. The question is how discourses of global climate change politics interrelated with local socio-economic dynamics and discourses.

\section{Global Discourses on Climate Change}

The United Nations Framework Conventions on Climate Change (UNFCCC) has remained a landmark for the beginning of climate change discourse in the global society ${ }^{2}$. It recognizes that the

2 The convention was adopted at the United Nations Headquarters, New York on the 9 May 1992. It was then made open for signature at Rio de Janeiro from 4 to 14 June 1992 for ratification, acceptance, 
climate system is a shared resource whose stability can be affected by industrial and other emissions of carbon dioxide and other Green House Gases (GHG). Under this convention, the governments are supposed to perform three tasks: a) gather and share information on GHG emissions, national policies and best practices; b) launch national strategies for addressing GHG emissions and adapting to expected impacts, including the provision of financial and technological support to developing countries; and c) cooperate in preparing for adaptation to the impacts of climate change. Later, the protocol to the UNFCCC was adopted at the third session of the Conference of the Parties (COP 3) in Kyoto, called Kyoto Protocol in Japan, on 11 December $1997^{3}$. The UNFCCC encouraged the industrialized countries to stabilize GHG emissions, while the protocol made parties to commit to do $\mathrm{so}^{4}$. Then, the detailed rules for the implementation of the Protocol were adopted at COP 7 in Marrakesh in 2001, and is called the "Marrakesh Accords".

approval or accession by states. The convention then was entered into force on 21 March 1994, and currently there are 194 Parties (193 States and 1 regional economic integration organization) for it. This convention sets an overall framework for intergovernmental efforts to tackle the challenge posed by climate change.

3 The Kyoto Protocol is an international agreement linked to the UNFCCC. It consists of 28 articles commonly agreed by the parties for greenhouse gas emission. It was made open for signature from 16 March 1998 to 15 March 1999 at United Nations Headquarters, New York. By that date the Protocol had received 84 signatures. The Protocol entered into force on 16 February 2005. It accounted in total for at least $5 \%$ of the total carbon dioxide emissions for 1990 of the Parties. Currently, there are 193 Parties (192 States and 1 regional economic integration organization) to the Kyoto Protocol to the UNFCCC.

4 According to this protocol, the parties of the protocol have to cut down their greenhouse gas emission by amount to an average of five per cent against 1990 levels over the five-year period 2008-2012.
Table 1: Some important date and events related to climate change

\begin{tabular}{|l|l|}
\hline Date & Events \\
\hline 1988 & $\begin{array}{l}\text { Intergovernmental Panel on Climate Change (IPCC) was } \\
\text { formed by joint efforts of World Meteorological } \\
\text { Organization (WMO) and United Nations Environment } \\
\text { Program (UNEP) to assess and prepare report on global } \\
\text { climate change with scientific facts, figures and analysis. } \\
\text { It published its first report in 1990. }\end{array}$ \\
\hline 1992 & $\begin{array}{l}\text { UNFCCC was adopted to stabilize global GHG } \\
\text { emissions in Reo De Geneiro. }\end{array}$ \\
\hline 1994 & $\begin{array}{l}\text { After UNFCCC was signed by 192 countries, it was then } \\
\text { enforced for the implementation of stabilize the } \\
\text { increasing GHG emissions in the world. It was basically } \\
\text { focused on the mitigation and adaptation to global } \\
\text { climate change. }\end{array}$ \\
\hline 1997 & $\begin{array}{l}\text { Under UNFCCC, the fifth convention held in Kyoto city } \\
\text { of Japan adopted "Kyoto Protocol” as legal binding for } \\
\text { 37 industrialized countries and the European community } \\
\text { for reducing GHG emissions . }\end{array}$ \\
\hline 2005 & $\begin{array}{l}\text { The concept Reducing Emissions from Deforestation } \\
\text { (RED) as mechanism for GHG emissions was proposed } \\
\text { by Costarica and Papua New Guinea in the 11 } \\
\text { sessions (Cop 11) held in Montreal, Canada. Under RED } \\
\text { concept, Subsidiary Body for Scientific and } \\
\text { Technological Advice (SBSTA) was formed to prepare } \\
\text { scientific report for RED. }\end{array}$ \\
\hline 2006 & $\begin{array}{l}\text { Forest Carbon Partnership Facility (FCPF) by World } \\
\text { Bank (WB) and United Nations REDD program to } \\
\text { support climate change vulnerable countries (less } \\
\text { developed and island countries) for climate change } \\
\text { assessment and adaptations were begun as a result of } \\
\text { COP 12 (scientific report which states 20 \% of GHG } \\
\text { emission is from developed countries and their forest } \\
\text { degradation and deforestation). }\end{array}$ \\
\hline $\begin{array}{l}\text { The concept of compensation by developed countries to } \\
\text { less developed countries for carbon emissions as a } \\
\text { concept of Reducing Emissions from Deforestation and } \\
\text { Forest Degradation (REDD) was introduced in COP 13 } \\
\text { held in Bali, Indonesia (called Bali Action Plan). These }\end{array}$ \\
\hline
\end{tabular}




\begin{tabular}{|l|l|}
\hline \multirow{2}{*}{2008} & $\begin{array}{l}\text { concepts introduced the initiatives for preparing country } \\
\text { proposals for carbon trade after 1012 as per the } \\
\text { implementation of Kyoto conventions, and National } \\
\text { Adaptation Plan of Action (NAPA) for mitigations and } \\
\text { adaptation for climate change. }\end{array}$ \\
\hline $\begin{array}{l}\text { In the supports of developed countries (mostly Norway, } \\
\text { Germany, USA), the preparations and implementation of } \\
\text { REDD programs in many of the less developed countries } \\
\text { were started. }\end{array}$ \\
\hline $2009 \begin{array}{l}\text { The concrete agreements on the amount of supports by } \\
\text { developed countries to less developed countries and the } \\
\text { basic level of temperature to be reduced could not be } \\
\text { done in the COP 15 held in Copenhagen Denmark. }\end{array}$ \\
$\begin{array}{l}\text { COP 16 in Cancun Mexico concluded with agreements } \\
\text { for the needs of deeper cuts in carbon emissions, but } \\
\text { could not specify any given mechanism for achieving the } \\
\text { pledges each country has made. }\end{array}$ \\
\hline
\end{tabular}

Source: UNFCCC 2006; Kyoto Protocol 1997; http://unfcc.int, http://www.environmentallawresource.com/2010/12/articles/air/ca ncan-or-cantcan-summary-of-cop-16/

Recognizing that developed countries are principally responsible for the current high levels of GHG emissions in the atmosphere as a result of more than 150 years of industrial activity, the Kyoto protocol places a heavier burden on developed nations. Under this protocol the countries have to meet their targets primarily through national measures. The Kyoto Protocol offers them an additional means of meeting their targets by way of three market-based mechanisms: a) emission trading-known as "the carbon market"; b) clean development mechanism (CDM); and c) joint implementation (JI). The mechanisms helped parties the options of stimulating green investment and help developing countries to meet the emission targets made by the developed countries in a cost-effective way.

Under the Protocol, actual emissions of the countries have to be monitored and the precise records have to be kept for the trades to be carried out. As a result the concept of Reducing Emission from Deforestation and forest Degradation (REDD) is now in the hot discourse. This protocol also provisioned and designed to assist the countries in adapting to the adverse effects of climate change. Under this, it facilitates for the development and deployment of techniques that can help increase resilience to the impacts of climate change is clearly provisioned. The adaptation fund was now established to finance adaptation projects and programs in developing countries that are parties to the Kyoto Protocol. The Fund is financed mainly with a share of proceeds from CDM project activities. This is now implemented and known as National Adaptation Plan of Action (NAPA). The discourses are in the process through series of conference of the parties called COP. Recently, the conference in Cancun Mexico, from 29 November to 10 December 2010 has encompassed the sixteenth conference of the parties (COP-16) with further negotiations between the parties upon the protocol.

REDD has been becoming the hot issues in climate change negotiation for the global societies today. Under this concept, developed country donors, corporations, nongovernmental organizations, and individuals will get compensation or compensate developing countries for their roles and contribution in forest emissions reductions through the agreements of market mechanisms. The payments of the contributions are based on the demonstrated emissions reductions through improved forest protection, sustainable forest management, and/or enhancement of carbon stocks. This mechanism is a key emissions mitigation strategy for extensive donor investments to prepare developing countries to contribute in their commitments of reducing the greenhouse gas emissions. For this, the developed countries are preparing for the huge amount of capital investment to the developing countries to compensate their contribution in their strategies for national land-use and forest-sector planning, stakeholder negotiations, tenure clarification, carbon brokering, national-level carbon accounting, and provision of funds and services to local actors as well.

\section{Climate Change Discourses in Nepal}

These days, the issues of climate change has been becoming as one of the major agenda of the country. There are some specific forms and nature of attempts against the adverse impacts of climate 
change in the country ${ }^{5}$. Namely there are three important government initiatives: REDD, NAPA and LAPA. These governmental initiatives are focused for climate change impacts and capacity enhancement and empowerment for adaptation in the country.

\subsection{National Adaptation Plan of Action (NAPA)}

NAPA project to climate change in Nepal was signed in November 2008 between the Ministry of Environment (MoE) and United Nation Development Project (UNDP) Nepal Country Office, as implementing partners of NAPA project with support from the Danish International Development Agency, Global Environment Fund, and UK Department of International Development. The NAPA Project had aimed to enable Nepal to respond strategically to the challenges and opportunities posed by climate change through the preparation of a NAPA document and development of a multi-stakeholder framework for NAPA implementation. It was backed up by a dedicated knowledge management and learning support.

The NAPA Project has three components: a) preparation of a NAPA; b) development and maintenance of a learning and knowledge platform to act as a clearing platform for climate change; and c) development of a multi-stakeholder framework of action on climate change. It has adopted an approach of multistakeholder engagement for vulnerability analysis, moving beyond the regional and national consultation meeting to generate and incorporate meaningful inputs from a wide range of stakeholders including vulnerable communities themselves. In order to promote and ensure multi-stakeholder participation in the NAPA process, six government-led thematic groups (TWGs) have been set up: a) agriculture and food security, b) climate-induced disasters, c)

${ }^{5}$ More than 57 projects on climate change have been already implemented (some of them are running) by different organizations in the countryhttp://www.climatenepal.org.np/main/?p=coordinate\&sp=climate change project). Similarly number of formal and informal networks are also actively working in the field. forests and biodiversity, d) water resources and energy, e) public health, and f) urban settlements and infrastructure. These are to support NAPA preparation process by undertaking information gathering and analysis, vulnerability assessments, facilitating engagement with various stakeholders.

NAPA Thematic Working Groups (TWG) have identified six priority project to address the urgent and immediate needs in Nepal for climate change adaptation. They are: 1) flood management; 2) construction of water retention structure along the Bagmati watershed area; 3) evidence based research for public health impact of climate change; 4) promotion and up-scaling of water multi use system; 5) integrated watershed management in Terai and 6) non-farm soil and water conservation.

\subsection{Local Adaptation Plan of Action (LAPA)}

Part of NAPA projects approach involves the generation of Local Adaptation Plans of Action (LAPA). The vision for LAPAs is to: a) develop a system of adaptation planning that enable communities to understand the changing uncertain future climatic conditions and engage effectively in the process of developing adaptation priorities, b) implement climate resilient plans, that are flexible enough to respond to changing climate and vulnerability conditions, and (c) inform sectoral programs and catalyze integrated approaches between sectors. This planning process seeks to establish a vertical link between the national-scale, top down assessments of current climate risks and future climate risks, with bottom-up assessments from community members themselvesinformed by local knowledge and geographical specificity. Therefore, LAPA is a plan prepared at local level by involving multi-stakeholder team including the vulnerable communities. The proposed LAPA would identify adaptation needs at the local level that focuses on reducing local-level climate risk and vulnerabilities and ways of increasing resilience. It would also focus on strengthening mechanisms for ensuring consolidated and coordinated adaptation responses at local levels through the existing planning process. Similarly, LAPAs is a vehicle to inform sectoral programs and catalyze cross-sectoral coordination and complementarities to build climate resilience. 
The development of LAPA has some basic principles. First one is for decentralized and bottom up planning; second is multi actor involvement; third is focusing on the local vulnerable and their adaptation; fourth is local level ownership; fifth is decentralized financial flow and implementation; sixth is low risk and high impact seventh is mainstream development; and eight is integrated planning and delivery. It is conceptualized that the LAPA process involves local government (e.g. in Nepal ward, VDC/Municipality, DDC), district or local level line agencies of the ministry and department (agriculture, forestry, water, women, health, infrastructure), civil society organization (INGOs, NGos, clubs, womens' group, cooperative, indigenous group), community and groups (community forestry user group, water user group, farmers group, farmers cooperative, livestock group, energy group, targeted groups), and vulnerable and poor households as stake-holders of the programs.

\subsection{Reducing Emission from Deforestation and Forest Degradation (REDD)}

Along with the participation in FCPF of WB, Nepal has already entered into the formal global climate change mechanism known as REDD. Under the support of international funding, the Ministry of Forest and Soil Conservation (MoFSC) has prepared its Readiness Plan of Idea Note (R-PIN) in April 2008 and submitted to WB. Based on the submitted R-PIN, WB then requested 18 selected countries (including Nepal) to prepare Readiness Preparation Proposal (R-PP). Nepal government (by MoFSC) has already prepared and submitted its R-PP to WB in April 2010 and now in the stage of implementing some pilot projects is different parts of the country.

The R-PP report in its vision stated like this "Our vision for Nepal's REDD strategy is that by 2013 and beyond, our GHG emissions resulting from deforestation and forest degradation will be significantly reduced by forest conservation and enhancement, by addressing the livelihoods concerns of poor and socially marginalized forest dependent people, and by establishing effective policy, regulatory and institutional structures for sustainable development of Nepal's forests under the forthcoming new constitutional framework". This report in its principle states that "R-PP will provide Nepal's roadmap for developing and implementing the REDD strategy, based on certain underlying principles agreed by representatives of all stakeholder groups in Nepal's forest sector". According to this report, the most drivers of deforestation and degradation (of total 9 direct and indirect drivers) are associated with underlying governance issues, such as weak natural resources management and administration, market failure response, rent seeking attitude, and structural socio-economic factors like poverty and limited livelihood options for forestdependent populations (MoFSC 2010: 40).

The preparation of REDD strategy as a three-year preparation plan to be developed by 2013 is clustered around five stages: a) Conducting of analytical studies (development of analytical studies to provide a scientific foundation on land use, the forestry sector, and the drivers of deforestation and forest degradation); $b$ ) Consultation for strategic options prioritization (national and subnational multi-sectoral and multi-stakeholder consultations, including the participation of representatives from the private sector, nongovernmental organizations, academia, government officials, indigenous peoples, local communities, Women, Dalits, Political parties and civil society. The strategic options includes five criteria: social economic, environmental, policy and governance, and technical); c) Economic and financial assessments of selected strategic options (economic and financial assessment, in which analysts will estimate the opportunity cost and the implementation and transaction costs for each selected option); $d$ ) Preparation and consolidation of the REDD Strategy (for strengthening institutional capacity, Preparation and dissemination of the REDD Strategy document and Endorsement and development of relevant plans); and $e$ ) Monitoring and evaluation (to ensure transparency and effectiveness of the REDD preparation process).

The proposed REDD implementation framework is based on the four key principles to ensure ownership of the process and effective implementation: a) Establish the link between carbon ownership rights and land tenure and clarify land tenure issues as a priority during the preparation phase; b) Utilize existing 


\section{8 | Jailab Kumar Rai}

institutional structures and arrangements (as far as possible) rather than creating parallel structures; c) Build on successful experiences of benefit sharing from Nepal and elsewhere, learn from ongoing pilots and encourage further piloting and sharing from these during the preparation phase; and d) Utilize multi-stakeholder mechanisms for REDD implementation and benefit-sharing at all levels.

\section{Overview of the Area}

Mustang is a representative district of Nepal's Himalayan region where growing climate change impacts have been reported both by media and researchers. It was once an independent kingdom, closely tied by language and culture of Tibet. Between $15-17^{\text {th }}$ century, it became strategic location for trade between the Himalayas and India. At the end of the 18th century the kingdom was annexed under the greater kingdom-Nepal. The district is divided into 16 VDCs with total population of 14,981 encompassing 3243 households (see annexes 1). These VDCs are divided into two major parts-the upper Mustang and Lower Mustang. In upper Mustang, free entrance to the outsider is restricted. One should get entrance permit to visit this part of the district. The lower Mustang is comparatively fertile in compare to drier upper Mustang. The whole Mustang is largely dry and arid with annual precipitation in the range of $250-400 \mathrm{~mm}$ due to its position in the rain shadow of the Annapurna and the Dhaulagiri range towards the south. Trees and plant species are ever more scarce and rare in both the regions and are further more scarce in upper Mustang. One gets images of desert when gets glimpse of the landscape of the region. The strong wind from morning until night blows from the south. These parts fall under the rain shadow and moreover the upper Mustang remains completely under the rain shadow, virtually untouched by the summer monsoon rains. Winter in Upper Mustang receives heavy snowfalls and even landslides.

Jomsom is the administrative headquarter of the district with a domestic airport accounting a very frequent flight from Pokhara. A few hours to the north from Jomsom is the village of Kagbeni, the last settlement in the unrestricted part of lower Mustang. Kagbeni is spiritually auspicious due to meeting two rivers one from north and another from east and functioned as an important trade stop in the past. The east of its steep trail lays the most important pilgrimage site known as Muktinath, "lord of salvation". In the North of Kagbeni, the restricted area of upper Mustang lies, which are also called Lo-Manthang. The rulers of this place have always been patrons of the Buddhist faith, continued since about 1425 . According to the population census 2001, the total population of the district is 14,981, spread between three towns and 16 VDCs with approximately thirty smaller settlements. The people in Mustang are either Thakalis, Gurung or in traditional Mustang, primarily the Tibetans. They mostly settle near the Kali Gandaki River, which is $2800-3900$ meter above sea level. The houses are clustered in some particular fertile corners. It is noticeable that all houses in this area has flatten roofs made of mud and clay, piled high with firewood collected in summer months. Villages have numerous Tibetan Buddhist monasteries.

The size of arable land is very small in the region (see annexes 2). It is found only in the riverbank and some were in the corner of the settlement areas. In comparison to the arable land, pasture land covers larger size resulting into the high possibility of animal husbandry (see annexes 3). Life in this region revolves around some agricultural production (see annexes 4), tourism, animal husbandry and trade. These days, their economic involvements have been widening and hence their society is becoming a very complex. Migration, abroad labor, official recruitment is newly emerging economic niche of the population. Along with the penetration of global trade and modern development infrastructure including politics and education, people of the region are becoming more critical and questioning. The effects of global climate change upon their usual socio-economic life have been noticeable phenomena for the people. Their skills of analysis and negotiations against unusual natural phenomena are an important part of their life to understand the links with global society. 


\section{Causes of Climate Change: Reflection of perception} from Mustang

It is observed that most of the people in Mustang are aware of the links of global and local climate change phenomena. The people met and interviewed in the visit responded that the adverse effects of climate change appearing in this region are because of the economic activities of the developed and rich countries (industrialized countries) of the world. They also shared their views that the compensation for the loss/effects of global climate change must be the responsibility of those countries. They are also aware of the inadequacy of government plans and policies regarding the transportation and other infrastructural development in the region as another cause of the climate change effects. They said that the government is not able to do and is honest to control the registration and entry of the old and pollutant vehicles in the district and the haphazard extension of road ways. They understood that these vehicles and the roadways are also bringing ruin in the local natural environment. They responded that such increasing pollution is resulting into the negative impact on environment and their life ways.

\section{Climate Change Experience: Reflection from Mustang}

People in Mustang with their day to day observation and experiences have clear ideas to notice the rapidly changing climate impacts in the region. They have very awful experiences of invariable climatic change since few years. They have been able to notice following things as new evidences related to natural environment and their perceptions linking with global climate change.

\section{Snowfalls}

The decline in regular and usual snowfall is one of the major observations of people in Mustang. According to them, usually the months from December to March they receive regular snowfall. But since few years, the local people have not been receiving the regular snowfalls in these months. Furthermore, they also showed their surprise to see the mountains and high peaks around and in Mustang are comparatively with less snow-cover. Previously, these peaks and mountains were covered with full of snow and snowfalls, but these days they notice that there are very less snowfalls and snow deposits. They responded that previously white peaks and mountains have been becoming black in their colors slowly and gradually. They also responded that in some years there is snowfall even in the spring season (the month of Chaitra in Nepali calendar), which is very surprising for their history.

\section{Hail and rainfall}

The longtime experiences and observation of Mustang people is to receive regular snowfall during winter seasons. The interesting thing they have shared in the interaction is since few years they are observing sometime a rainfall and hail instead of snow. For them it is very surprising because they had never heard and seen hail in this place.

\section{Damage of apple production}

Apple production is one of the famous and important economic activities of Mustang people. But, they responded that these days its production is declining because of some time heavy snowfall, some time hails and some time diseases. They responded that these days different unidentified types of insects and diseases are destroying the apple productions.

\section{Appearance of new diseases in crops and fruit production}

The farmers of Mustang are accounting for new and unknown diseases on their farmland crops and fruits. They are noticing different types of insects, which are very new for them and never seen before, are damaging their fruits and crop production. They responded that previously they never suffered from the diseases in the potatoes and buckwheat production, but these days they are suffering from different kind of diseases on these crops productions.

\section{Production of new varieties of crops}

They said that some of the varieties of crop productions were not common to them. But these days they are producing new varieties of crops in their own farmlands. The production of chilly is very surprising to them. Regarding this production, a local person said that in the earlier days chilly is collected/bought from other parts 
(than Mustang) for their ritual needs and use but these days they are easily producing this variety in their own farmlands. Similarly, the cucumber and maize were never produced in the place but since few years back they are producing these crops in their own farmlands.

\section{Warming Increase}

They are also noticing the increasing warm throughout the year. They said that the days in the months of October and November were never warm, but since few years it is becoming warmer and warmer every year. They responded that the sunlight these days are observed as much hotter than previously. They are clearly noticing that the warm of the days are gradually increasing.

\section{Appearance of House flies, mosquitoes and other insects}

The people of Mustang, since few years, are surprising to see house flies and mosquitoes in the areas. Previously, these creatures/insects were not seen and existed in the areas but they are surprising to see their number increasing every year. It is also observed that some of the mosquitoes and flies were there during the field visit. According to them these, before few years back, were never seen in the areas. Some insects and butterflies never seen before are also appearing in the area.

\section{Flowering and fruiting seasons changed}

According to the people in Mustang, flowering and fruiting of the crops and fruits (like buckwheat, apple) is becoming earlier and the duration of fruiting is also becoming shorter than the previous. Most of the people of the area said that in the past vegetables were produced once in a year, but these days farmers are able to plant and harvest vegetables twice a year.

\section{Forms and nature of mist changed}

The people of Mustang are clearly able to notice out the changing nature and forms of mist in the area. Previously, the amount of mist was quite sufficient to keep the soil wet but these days the amount of mist is decreasing and due to which the soil in the farmland is becoming drier every day and resulting into the low productivity and desertification of pasture lands.

\section{Irregular water-flow in the rivers}

The agricultural lands in the villages of Mustang are irrigated and drained from a number of small rivers. They normally have their own traditional irrigation canals from those rivers. But these days they are observing the irregularity of the amount of water-flows in those rivers. They now cannot predict the quantity of water-flow in these rivers. Sometime they see unexpected floods, some time high and sometime very low current of water-flow.

\section{Impacts of Climate Change: Reflection from Mustang}

The economic and social life of people in Mustang is gradually encompassing with negative effects posed by the global climate change. They are experiencing these effects in different forms and nature. Some of the major impacts they noticed are as below.

\section{Cattle rearing}

It is observed that the traditional occupation of cattle rearing in Mustang is highly affected by the impacts of global climate change. The number of their cattle is declining due to the dryness in their pasture lands. The cattle are suffering from different kinds of diseases which were never seen before. Because of this, they are selling their cattle to reduce the number of cattle to be safe from the risk of unexpected and untimely death, last year 800 chaygra, sheep, died in Muktinath VDC.

\section{Crop varieties and season of planting}

The rapidly changing nature of weather condition resulting into the change in the seasonal calendar is making the people of Mustang confused of planting seasons and varieties of crops to be planted. The increasing dryness of their farmland is becoming another part of their problem. Because of this, productions of vegetable, fruits, crop varieties etc are becoming a challenging task for them. Because there are newly introduced varieties and hence they are unknown about the problems for its productions. The appearances of different types of insects and diseases are also causing the damage of their crops and fruit productions. 


\section{Desertification of pasture lands}

People in Mustang are observing that their traditional pasture lands are gradually decertifying every years; which is affecting their traditional pasture rearing culture in the areas. According to the local people, previously there used to lots of snow falls and deposits in upper parts of the settlement areas including sufficient mist falls at nights. They responded that the deposited snowfall (permanent and temporary) and mist at night were able to make the pasturelands wetted and fertile for grasses. These days they have been observing that there is less and somewhere no snowfall and snow deposits in those places including very less mists at night. Because of which previous used pasturelands are being converted into the desert lands resulting into the negative effect on cattle rearing culture.

\section{Decline in agricultural production}

The people in the Mustang responded that their traditional agricultural production has been declining. Regarding this, they have simply a couple of understandings. One is irregular and decline of snowfall and hail, due to which their farmland is becoming dry. Second is the appearance of new diseases and insects, which are destroying their agricultural productions. So, changing patterns of snowfalls, mist and appearing diseases are becoming their great challenge for agricultural production. They responded that such changes are appearing along with the increments of warmth in the region.

\section{Unexpected flooding and damage}

The people of Mustang are suffering from unexpected floods (resulting into the sand deposits and water-flow direction change) in the rivers and its damages and destructions of development infrastructures like roadways, irrigation cannels, bridges, farmlands, human settlements and others. They responded that such problems are seen in the local rivers like Marpha river, Tucche river, Shyang river and others since few years back. The fluctuation of water-flows resulting into such destruction is mostly observed in the rivers which flow from north to the south directions.

\section{Impacts of hail and rainfall}

The irregular snowfall in the region is gradually resulting into the hail and rainfall. These natural changes have negative effects in the life ways of Mustang people. It is particularly affecting to their traditional houses. Because the roof of their houses are flat covered with mud and clay. The rainfall (if there will be) with hail may be disastrous to them, because it damages their traditional houseroofs. They are worried about the damage of their house-roofs by rainfall if it increases. It is also sure that if the rainfall increases, people in Mustang will be adversely affected by the damage of their traditional house-roofs.

\section{Appearance of new human diseases}

The people of Mustang are noticing different kinds of insects, flies, mosquitoes. Apart from that, they are suffering from common illness and sickness like common cold, eye swelling diarrhea etc. The number of suffering from these diseases is increasing every year.

\section{Appearance of wild animals in farmland}

According to the local people, wild animals like snow-leopard, jackal and other small creatures, which were found and seen only in the forest and outside the human settlement areas, have been started to seen in their farmlands and settlement areas since few years. These days they are suffering from the attack to their domestic animals by snow-leopard. They also responded that even some time it tries to injure human beings as well. For them, it is simply because of the dryness of pasture lands resulting into the decline of grasses and other resources for their survivals inside their previous niche. They reported that these wild animals are gradually losing their fear and becoming bold to challenge the human lives.

\section{Local Needs and Demands: Reflection from Mustang}

It is observed that the people of the Mustang are quite aware of raising their local climate change issues in the interactions and gatherings. The strong voices were raised by local people to consider such studies and findings for formulation and 
implementation of plan and policies related to the issues. The unified voices demanding for frequent visit and studies of experts and researchers from the country and abroad to study the people and their problems growing with the climate change impacts, have remained an important observation in the visit. They also responded that about such programs (study visit) prior information to local people is necessary so that the consolidated ideas and thinking of the local people could be drawn out. This means the people met in the visit were highly demanding and expecting external support in climate change impacts appearing in the region and also found that they are more optimistic for it. They also showed their skepticism on whether the government and other agencies will address their needs and demands they have shared. The formulation and implementation of appropriate plans and policies regarding the issues they have shared had remained another important observation of the visit.

The interaction with the people in Mustang remained quite fruitful for observation of local understanding and recommendation for way ahead in local problem solution. Firstly, their strong argument remained with the use of available water resources for hydropower, irrigation of their land and forest resources in the dry places. Secondly, the participants argued for the formulation and implementation of appropriate plans and policies regarding the potentials of tourism industry especially contrasted with road construction and trekking tourism, local people do not have common understanding but some suggest alternative trek trail be constructed for trekkers. Thirdly, the participants argued for identification, proper management and utilizations of available natural resources like minerals (coal and gas), herbs and natural resources for generating job opportunities and capacities for adaptation. Fourthly, the participants raised their concerns about the needs of special and specific climate change adaptation programs to support local efforts on economic activities like livestock, apple farming, snow and water deposits, promotion of snow and water harvesting technologies to reduce water stresses, conservation of local forest and plantations to serve a viable option to protect soil erosion and water conservation, wild fire control policy and wildfire control mechanism, replacement of the use of firewood by available alternative fuel saving technologies like gas, kerosene, improved cooking stoves, biogas plants and solar cookers. Fifthly, the common voices of participants and interviewee was observed as their appeals for effort to be made for external supports for the regions. It is felt that the participants in the interactions and people encountered in the visit had well informed knowledge about climate change and are more optimistic for external supports.

\section{People of Mustang Beyond the World}

Roncoli et al (2009:90) said that the human body's senses are the important avenues to know the local weather manifestation in the form of rain, hail, snow, wind, and temperature. The people of Mustang are quite aware and experienced with such an avenues appearing in their place. Local people since few years able to decode the changing weather patterns and its impacts in their day to day socio-economic cosmology. Their perceptions on how climate is changing and what should be done for combating against it is quite noteworthy and interesting. Their cosmogonist views upon the climate change and its impacts discussed in earlier chapters indicate that they are in the path of advancing their opinions and understandings of the issues along with the dynamics of global discourses. It is seemed that along with the global climate change discourses gaining wider attentions since the beginning of $21^{\text {st }}$ century (or after the formation of IPCC and UNFCCC advanced with Kyoto Protocol), the socio-economic dynamics of Mustang people have also been simultaneously changed. The people of Mustang have lots of useful anecdotes need to understand and incorporate into the advancement of policy uptakes for adaptive capabilities.

The broader observation of global climate change discourses and socio-economic dynamics developing in Mustang indicates that there is embeddedness between these two different worlds. Here, the ideas of McCay (2002: 362) may be useful in understanding the interrelations of socio-economic discourses happening in the Mustang and the upcoming global climate change politics. She said that the acting and decision making individuals and social groups are embedded and the ideas of people's perceptions and experiences often are linked with the national and global politics 
occurring and exhorting across the human societies. She further highlights that the aspiration and anxieties about the future in relation to climate change (ibid: 104) is associated with the national agendas set forth on the basis of global politics and negotiations. Moreover, the individual researchers are also not an independent academic researcher, but as professionally embedded with the institutions and politics around him as institutional embeddedness (ibid: 104-105). The voices and demands of the people met and listened during the visit are replication of the concept 'embeddedness' as their understanding on climate change is fascinating with the global and national discourses and dynamics on climate change. Regarding impacts of global climate change and appropriate adaptation measures, the people in Mustang expect actions and support from the national and international communities. Moreover, the national initiatives carrying out by the government (like REDD, NAPA, LAPA) are determinants of global political negotiations and its outcomes.

The activities initiated by the national government of course are based on the guidelines and frameworks of the global politics and needs. Similarly, the climate change related activities in Mustang, of course, will be based on the global climate change adaptation agreements and other form of political negotiations. It is channelized through the national governments and other implementing organizations, institutions or any form of other agents. Here, it means the issue of climate change for global, national and local society is becoming interrelated and common agenda of efforts. One could not and should not make an independent efforts and attempts to come on the stage of successful combating. The issue of effects, impacts and political discourses of climate change has been becoming a common agenda of global society encompassing the needs and compulsion of interconnected attempts and efforts. But the important issues for anthropological studies with its disciplinary lenses is to what extent the local knowledge and experiences will be acknowledged in such global political discourses of climate change adaptation. It will be important avenues of anthropological engagements for critical and creative reflections and of contributions to the climate change discourses in the days to come.

\section{8 | Jailab Kumar Rai}

Peterson and Broad (2009:81) say that climate change discourse has the potential to obfuscate unequal power relations, letting governments off the hook for poor environmental and social policies and practices. The climate change discourse developing in Nepal and its peripheries, like in Mustang, is opening up the number of avenues for way ahead. Interface between the experiences ${ }^{6}$, understanding and expectation of people in Mustang and the greening national and international politics of climate change indicate the same. The number of expectations and immediate needs of local people are appearing along with the macro political discourses. This discourse of course will set forth a new paradigm of global, national and local environmental governance. The idea of realignment of current local, national and international policies to provide world governance for collective survivals (ibid: 62) against the growing global climate change impacts may be an important hallmark asserted from the review and analysis of global and local dynamics and discourses on climate change issues.

Bolin (2009: 237) illustrates the successful cooperation and collaboration of national and international organizations for the survival of communities in Andes. Similarly, Hitchcock (2009: 257-259) from his study among the San (Bushmen, Basarw) of the Kalahari desert also found that almost all of his respondents were saying that government, national and international organizations should be responsible to act against climate change impacts upon the local people. Button and Peterson (2009:338), based on the experiences of the innovative, collaborative and successful project approach forged by the members of the Grand Bayou-Louisiana community project in partnership with social and physical scientists, also concluded that such projects enable communities to uncover and develop their capacity for self-preservation and overthrow the repressive mantle of 'vulnerability' and the perception of helplessness in order to imagine a different future and moreover cultivates and nourishes the social fabric of a

$6 \quad$ As explained in earlier chapter, people in Mustang have lot of experiences in how climate is changing. They have observed the change in snowfall, hail, agriculture, flood, different kind of diseases etc. 
community, thereby enabling them to maximize their use of their social capital in building the foundations of resiliency. It is plausible to interlink the national climate change discourses with the context of what local people-like in Mustang, think, expect, demand and need for the climate change resilience. But the climate change politics enriching in the country seems to be more critical in the sense of whether the participation of local people in the future endeavour will be acknowledged. The anecdotes observed and sensed by the Mustang people may be the important part of knowledge for future directions. As a response against the local voices, CA members participated in the Mustang visit made their strong commitments to raise the issues at all level of policy debates including parliament, public forums, government policy processes, media, including the constitution building processes in Nepal. So, this is great challenge for planners, policy makers, academics and others that how and to what extent such knowledge and experiences could be explored and used for future actions.

\section{Conclusion}

The global discourses on climate change are equally gaining its attention in national and local discourses. This is encompassing through the diverse form of debates and discussions in all sections of societies. In this context, one needs to look and understand the issues with the links of discourses developing from micro-macro phenomenon. It can be said that one cannot understand the issues without proper consideration of these whole dynamics and discourse. This means the local or national or global issues cannot be kept in isolation. Hence, the issue is becoming a means through which environmental, political, economical, social and even developmental approaches and actions of either a local community or a nation is interwoven with the discourses and dynamics developing in the global society. Regarding climate change, there may be lot of knowledge and experiences with the local people. So, the attempts to advance for the adaptation to climate change highly requires the insights developed and enriched from vary local to the global societies.

\section{Acknowledgement}

I would like to thank the British Embassy to Nepal, for financial support for this visit. I also would like to thank people of Mustang for their cooperation during the visit. The participants during the Mustang Visit includes the Constituent Assembly members: Sunil Babu Panta (NCPUnited), Binda Pandey (CPN-UML), Akkal Bahadur Thing (UCPNMaoist), Tilak Bahadur Thapa Magar (CPN- ML), Khem Bahadur Bum (UCPN-Maoist), Sita Devi Baudel (UCPN-Maoist), Radha Timilsina (CPN-UNIFIED), Renu Chand (UCPN-Maoist), Ratna Gurung (CPNUML), Seela Katila (CPN-UML), Renu Dahal (UCPN-Maoist), Laxmi Pariyar (Nepali Congress), Dina Upadhyay (Nepali Congress), Chandrika Pd Yadav (M J Forum), and Chandra Bdr Gurung (UML) also deserve especial thanks.

\section{References}

Adger, Neil W.; Paavola, Jouni; and Haq, Saleemul (2006).

Towards Justice in Adaptation to Climate Change. In:

Adger, Neil W.; Paavola, Jouni; Haq, Saleemul; and Mace M. J. (ed.), Fairness in Adaptation to Climate Change.

Massachusetts Institute of Technology, pp. 1-19.

Baer, Hasan (2008). Global Warming as a By-Product of the Capitalist Treadmill of Production and Consumption: The Needs for an alternative Global System. In: The Australian Journal of Anthropology, Vol. 19, 1 pp. 58-61.

Baer, Paul (2006). Adaptation: Who Pays Whome?. In: Adger, Neil W.; Paavola, Jouni; Haq, Saleemul; and Mace M. J. (ed.), Fairness in Adaptation to Climate Change. Massachusetts Institute of Technology, pp. 131-154.

Barlett, Peggy F.; and Steward, Benjamin (2009). Shifting the University: Faculty Engagement and Curriculum Change. In: Crate, Susan A.; and Nuttall Mark (ed.) Anthropology and Climate Change. Left Coast Press, Inc., USA, pp. 356-369.

Barnett, Jon (2006). Climate Change, Insecurity, and Injustice. In: 
Adger, Neil W.; Paavola, Jouni; Haq, Saleemul; and Mace M. J. (ed.), "Fairness in Adaptation to Climate Change". Massachusetts Institute of Technology, pp. 115-130.

Batterby, Simon (2008). Anthropology and Global Warming: The Needs for Environmental Engagement. In: The Australian Journal of Anthropology, Vol (19:1), pp. 62-68.

Bohren, Lenora (2009). Car Culture and Decision Making: Choice and Climate Change. In: Crate, Susan A.; and Nuttall Mark (ed.) Anthropology and Climate Change. Left Coast Press, Inc., USA, (pp. 370-379).

Bolin, Inge (2009). The Glacier of the Andes are Melting:

Indigenous and Anthropological Knowledge Merge in Restoring Water Resources. In: Crate, Susan A.; and Nuttall Mark (ed.) Anthropology and Climate Change. Left Coast Press, Inc., USA, (pp. 228-239).

Broadbent, Noel D.; and Lantto, Patrik (2009). Terms of Engagement: An Artic Perspectives on the Narratives and Politics of Global Climate Change. In: Crate, Susan A.; and Nuttall Mark (ed.) Anthropology and Climate Change. Left Coast Press, Inc., USA, (pp. 341-355).

Button, Gregory V.; and Peterson, Kristina (2009). Participatory Action Research: Community Partnership with Social and Physical Scientists. In: Crate, Susan A.; and Nuttall Mark (ed.) Anthropology and Climate Change. Left Coast Press, Inc., USA, (pp. 327-340).

Colombi, Benedict J. (2009). Salmon Nations: Climate Change and Tribal Sovereignty. In: Crate, Susan A.; and Nuttall Mark (ed.) Anthropology and Climate Change. Left Coast Press, Inc., USA, (pp. 186-196).

Crate, Susan A. (2008). Gone the Bull of Winter? Grappling with the Cultural Implications of and Anthropology's Role (s) in Global Climate Change. In: Current Anthropology, Vol (49: 4), pp. 569-595).
Crate, Susan A. (2009). Gone the Bull of Winter? Contemplating Climate Change's Cultural Implications in Northeastern Siberia, Russia. In: Crate, Susan A.; and Nuttall Mark (ed.) Anthropology and Climate Change. Left Coast Press, Inc., USA, pp: 139-152.

Crate, Susan A.; and Nuttall Mark (2009) Epilogue: Anthropology, Science, and Climate Change Policy. In: Crate, Susan A.; and Nuttall Mark (ed.) Anthropology and Climate Change. Left Coast Press, Inc., USA (pp. 394-400).

Crate, Susan A.; and Nuttall Mark (2009). Introduction: Anthropology and Climate Change. In: Crate, Susan A.; and Nuttall Mark (ed.) Anthropology and Climate Change. Left Coast Press, Inc., USA, pp: 9-38.

Danish International Development Assistance (2008). Climate Change Screening of Danish Development Cooperation with Nepal (A draft report). Ministry of Foreign Affairs of Denmark Danish International Development Assistance (Danida)

Das, Sushil Kumar (2007). Climate Change: An Indian Perspective. India: Cambride Press.

Dessler, Andrew E.; and Parson, Edward A. (2006). The Science and Politics of Global Climate Change: A Guide to the Debate (sixth printing, 2008). UK:Cambridge University Press.

Dow, Kristin; Kasperson, Roger E.; and Bohn, Marie (2006). Exploring the Social Justice Implications of Adaptation and Vulnerability. In: Adger, Neil W.; Paavola, Jouni; Haq, Saleemul; and Mace M. J. (ed.), Fairness in Adaptation to Climate Change. Massachusetts Institute of Technology, pp. 79-96.

Finan, Timothy (2009). Storm Warnings: The Role of Anthropology in Adapting to Sea-Level Rise in Southeastern Bangladesh. In: Crate, Susan A.; and Nuttall 


\section{4 | Jailab Kumar Rai}

Mark (ed.) Anthropology and Climate Change. Left Coast Press, Inc., USA, (pp. 175-185).

Fiske, Shirley J. (2009). Global Change Policymaking from Inside the Beltway: Engaging Anthropology. In: Crate, Susan A.; and Nuttall Mark (ed.) Anthropology and Climate Change. Left Coast Press, Inc., USA, (pp. 277-291).

GN/MoFSC (2010). Nepal's Readiness Preparation Proposal (RPP). Government of Nepal/Ministry of Forest and Soil Conservation, Katmandu.

Government of Nepal (2010). National Adaptation Programme of Action (NAPA) to Climate Change (workshop report on Establishing a National Climate Change Knowledge Management Platform in Nepal. Government of Nepal Ministry of Environment.

Government of Nepal [GN] (2010). National Adaptation Programme of Action (NAPA) to Climate Change. Government of Nepal Ministry of Environment

Green, Donna (2009). Opal Waters, Rising Seas: How SocioCultural Inequality Reduces Resilience to Climate Change Among Indigenous Australians. In: Crate, Susan A.; and Nuttall Mark (ed.) Anthropology and Climate Change. Left Coast Press, Inc., USA, (pp. 218-227).

Haq, Saleemul; and Khan, Mizan R. (2006). Equity in National Adaptation Programs of Action (NAPAs): The Case of Bangladesh. In: Adger, Neil W.; Paavola, Jouni; Haq, Saleemul; and Mace M. J. (ed.), Fairness in Adaptation to Climate Change. Massachusetts Institute of Technology, pp. 181-200.

Hassan, Fekri A. (2009: Human Agency, Climate Change, and Culture: An Archaeological Perspective. In: Crate, Susan A.; and Nuttall Mark (ed.) Anthropology and Climate Change. Left Coast Press, Inc., USA, pp: 39-69.

Hensshaw, Anne (2009). Sea Ice: The Socio-Cultural Dimensions of Melting Environment in the Artic. In: Crate, Susan A.; and Nuttall Mark (ed.) Anthropology and Climate Change. Left Coast Press, Inc., USA, (pp. 153-165).

Hitchcock, Robert K. (2009). From Local to Global: Perceptions and Realities of Environmental Change Among Kalahari San. In: Crate, Susan A.; and Nuttall Mark (ed.) Anthropology and Climate Change. Left Coast Press, Inc., USA, (pp. 250-262).

IGES (2008). Climate Change Policies in the Asia Pacific: Reuniting Climate Change and Sustainable Development. Institute for Global Environmental strategies (IGES). Japan: Sato Printing Co. Ltd

Intergovernmental Panel on Climate Change (IPCC) (2007 a). Climate Change 2007: The physical Science Basis, Sumery for Policy Makers: Contribution of Working Group I to the fourth Assessment Report of the IPCC. Paris.

International Institute for Sustainable Development (2010). Earth Negotiations Bulletin:A reporting Service for Environment and Development Negotiations: Cope 16 Final. (httt://www.iisd.ca/climate/cop16/).

IPCC (2007a). Working Group II Contributions to the Intergovernmental Panel on Climate Change 2007: Climate Change Impacts, Adaptation and Vulnerabiity. Summery for Policy Makers. Available at:http://www.ipcc.ch [assessed January 15, 2011].

IPCC (2007b). Climate Change 2007: Climate Change Impacts, Adaptation and Vulnerability, Summery of policy makers: Contribution of Working Group II to the Fourth Assessment Report of the IPCCC. Brussels.

Jacka, Jerry (2009). Global Averages, Local Extremes: The Subtleties and Complexities of Climate Change in Papua New Guinea. In: Crate, Susan A.; and Nuttall Mark (ed.) 


\section{6 | Jailab Kumar Rai}

Anthropology and Climate Change. Left Coast Press, Inc., USA, (pp. 197-208).

Jennaway, Megan (2008). Apocalypse on You! Millenarian Frenzy in Debates of Global Warming. In: The Australian Journal of Anthropology, Vol (19:1), pp. 68-73.

Lazrus, Heather (2009). The Governance of Vulnerability: Climate Change and Agency in Tuvalu, South Pacific. In: Crate,

Susan A.; and Nuttall Mark (ed.) "Anthropology and Climate Change”. Left Coast Press, Inc., USA, (pp. 240-249).

Leay, Neil (2006). A Welfare Theoretic Analysis of Climate Change Inequities. In: Adger, Neil W.; Paavola, Jouni; Haq, Saleemul; and Mace M. J. (ed.), "Fairness in Adaptation to Climate Change”. Massachusetts Institute of Technology, pp. 155-178.

Leichenko, Robin; and Brien, Karen O. (2006). Is it appropriate to Indentify Winners and Losers? In: Adger, Neil W.; Paavola, Jouni; Haq, Saleemul; and Mace M. J. (ed.), Fairness in Adaptation to Climate Change. Massachusetts Institute of Technology, pp. 97-114.

Linneroth-Bayer, Joanne; and Vari, Anna (2006). Extreme Weather and Burden Sharing in Hungary. In: Adger, Neil W.; Paavola, Jouni; Haq, Saleemul; and Mace M. J. (ed.) Fairness in Adaptation to Climate Change. Massachusetts Institute of Technology, pp. 229-260.

Mace, M. J. (2006). Adaptation Under the UN Framework Conversion on Climate Change: The International Legal Framework. In: Adger, Neil W.; Paavola, Jouni; Haq, Saleemul; and Mace M. J. (ed.), Fairness in Adaptation to Climate Change. Massachusetts Institute of Technology, pp. 53-76.

McCay, Bonnie (2002). Emergence of Institutions for the Commons: Context, Situations and Events. In: Ostrom, Elinor; Dietz, /Thomas; Dolsak, Nives; Stern Paul C.;

Stonich, Susan; and Weber Elke U. (ed.), The Drama of the Commons. National Academy Press, Washington. Pp. 361-402.

Milton, Key (2008). Fear for the Future. In The Australian Journal of Anthropology, Vol. (19:1), pp. 73-77.

Milton, Key (2008). Introduction. In. The Australian Journal of Anthropology, Vol. (19:1), pp. 57-58.

Ministry of Environment (2010). NAPA Bulletin. March-May 2010. Government of Nepal, Ministry of Environment.

Minnegal, Monica; and Dwyer, Peter (2008). Fire, Blood, Fish and the Uncertainty Paradox. In The Australian Journal of Anthropology, Vol. (19:1), pp. 77-81.

Morino, Elizabeth; and Schweitzer (2009). Talking and Not Talking About Climate Change in Northeastern Alaska. In: Crate, Susan A.; and Nuttall Mark (ed.) Anthropology and Climate Change. Left Coast Press, Inc., USA, (pp. 209217).

Nuttall, Mark (2009). Living in a World of Movement: Human Resilience to Environmental Instability in Greenland. In Crate, Susan A.; and Nuttall Mark (ed.) Anthropology and Climate Change. Left Coast Press, Inc., USA, (pp. 292310).

Oliver-Smith, Anthonony (2009). In Crate, Susan A.; and Nuttall Mark (ed.) Anthropology and Climate Change. Left Coast Press, Inc., USA, pp: 11-136.

Paavola, Jauni (2006). Justice in Adaptation to Climate Change in Tanzania. In: Adger, Neil W.; Paavola, Jouni; Haq, Saleemul; and Mace M. J. (ed.), Fairness in Adaptation to Climate Change. Massachusetts Institute of Technology, pp. 201-222.

Paavola, Jauni; Adger, Neil W.; and Haq, Saleemul (2006). Multifaceted Justice in Adaptation to Climate Change. In: Adger, Neil W.; Paavola, Jouni; Haq, Saleemul; and Mace 
M. J. (ed.), Fairness in Adaptation to Climate Change. Massachusetts Institute of Technology, pp. 263-278.

Peterson, Nicole; and Broad, Kenneth (2009). Climate and

Weather Discourse in Archaeology. Crate, Susan A.; and Nuttall Mark (ed.) Anthropology and Climate Change. Left Coast Press, Inc., USA, pp: 70-86.

Phelps, Jacob; Edward L. Webb; and Arun Agrawal (2010). Does REDD+ Threaten to Recentralize Forest Governance?. Policy Forum, Vol. 338. www.sciencemag.org

Puntenney, P. J. (2009). Where Managerial and Scientific Knowledge Meet Socio-Cultural Systems: Local Realities, Global responsibilities. In: Crate, Susan A.; and Nuttall Mark (ed.) Anthropology and Climate Change. Left Coast Press, Inc., USA, (pp. 311-326).

Ronkoli, Carla; Crane, Todd; and Orlove, Ben (2009). Fielding Climate Change in Cultural Anthropology. In Crate, Susan A.; and Nuttall Mark (ed.) Anthropology and Climate Change. Left Coast Press, Inc., USA, pp: 87-115.

Rose, Deborah Bird (2008). Love in the Time of Extinctions. In The Australian Journal of Anthropology, Vol (19:1), pp. 81-84.

Schneider, Stephen H.; and Lane, Janica (2006). Dangers and Thresholds in Climate Change and the Implications for Justice. In Adger, Neil W.; Paavola, Jouni; Haq, Saleemul; and Mace M. J. (ed.), Fairness in Adaptation to Climate Change. Massachusetts Institute of Technology, pp. 23-52.

Stockenberger, Nicole A. (2009). Anthropologists Engaging in Climate Change Education and Outreach: Curating Thin Ice-Innuit Traditions Within a Changing Environment. In: Crate, Susan A.; and Nuttall Mark (ed.) Anthropology and Climate Change. Left Coast Press, Inc., USA, (pp. 380393).

\section{8 | Jailab Kumar Rai}

Strauss, Sarah (2009). Global Models, Local Risks: Responding to Climate Change in the Swiss Alps. In Crate, Susan A.; and Nuttall Mark (ed.) Anthropology and Climate Change. Left Coast Press, Inc., USA, (pp. 166-174).

Taussaint, Sandy (2008). Climate Change, Global Warming and Too Much Sorry Bussiness. In: The Australian Journal of Anthropology, Vol (19:1), pp. 84-88.

Thomas, David S. G.; and Twyman, Chasca (2006). Adaptation and Equity in Resource Dependent Societies. In Adger, Neil W.; Paavola, Jouni; Haq, Saleemul; and Mace M. J. (ed.), Fairness in Adaptation to Climate Change. Massachusetts Institute of Technology, pp. 223-228.

UNFCCC (United Nations Framework Convention on Climate Change)(2007). Decision-/CP.13 Bali Action Plan, [Online] Available at: http://unfccc.int/files/meetings/ cop_13/application/pdf/cp_bali_action.pdf [accessed 15 June 2008].

UNFCCC (United Nations Framework Convention on Climate Change) (2008). Kyoto Protocol Status of Ratification, [Online] Available at: http://unfccc.int/files/Kyoto _protocol/status_of_ratification/application/pdf/kp_ratifica tion.pdf [accessed 1 August 2008].

Wigley T.M.L. (1999). The Science of Climate Change. Washington DC: Pew Centre on Global Climate Change. 
Annexes 1: Distribution of population in Mustang by different categories

\begin{tabular}{|l|c|c|c|c|c|c|}
\hline $\begin{array}{c}\text { Name of } \\
\text { the VDCs }\end{array}$ & $\begin{array}{c}\text { Total } \\
\text { house } \\
\text { holds }\end{array}$ & $\begin{array}{c}\text { Total } \\
\text { Population }\end{array}$ & $\begin{array}{c}\text { Economically } \\
\text { active } \\
\text { population }\end{array}$ & $(\%)$ & Illiterate & $(\%)$ \\
\hline Charang & 132 & 723 & 389 & 53.8 & 328 & 45.3 \\
\hline Chhonhup & 194 & 1088 & 710 & 65.2 & 584 & 53.7 \\
\hline Chhoser & 170 & 769 & 536 & 69.6 & 428 & 55.6 \\
\hline Chhusang & 197 & 901 & 451 & 50.0 & 294 & 32.7 \\
\hline Dhami & 160 & 891 & 520 & 58.4 & 502 & 56.4 \\
\hline Jhong & 93 & 491 & 259 & 52.7 & 168 & 34.2 \\
\hline Jomsom & 413 & 1589 & 1176 & 74.0 & 381 & 24.0 \\
\hline Kagbeni & 262 & 1241 & 763 & 61.5 & 456 & 36.8 \\
\hline Kowang & 172 & 699 & 520 & 74.4 & 227 & 32.5 \\
\hline Kunjo & 149 & 709 & 454 & 64.1 & 245 & 34.6 \\
\hline Lete & 191 & 955 & 697 & 73.0 & 334 & 35.0 \\
\hline $\begin{array}{l}\text { Lo- } \\
\text { manthang }\end{array}$ & 180 & 907 & 557 & 61.4 & 434 & 47.8 \\
\hline Marpha & 437 & 1693 & 1119 & 66.1 & 453 & 26.7 \\
\hline Muktinath & 193 & 940 & 644 & 68.5 & 386 & 41.0 \\
\hline Surkhang & 132 & 692 & 331 & 47.8 & 253 & 36.6 \\
\hline Tukuche & 168 & 693 & 452 & 65.2 & 230 & 33.1 \\
\hline Total & $\mathbf{3 2 4 3}$ & $\mathbf{1 4 9 8 1}$ & $\mathbf{9 5 7 5}$ & $\mathbf{6 3 . 9}$ & $\mathbf{5 7 0 3}$ & $\mathbf{3 8 . 1}$ \\
\hline
\end{tabular}

Source: CBS 2001
Annexes 2: Distribution of land in Mustang by different categories

\begin{tabular}{|c|c|c|c|c|c|c|c|c|c|}
\hline \multirow{3}{*}{ 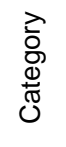 } & \multicolumn{8}{|c|}{ Land categories and total areas (in hectare) } & \multirow{3}{*}{ Total } \\
\hline & \multicolumn{5}{|c|}{ Arable Land categories } & \multirow{2}{*}{$\begin{array}{c}\text { Pasture } \\
\text { land }\end{array}$} & \multirow{2}{*}{$\begin{array}{l}\text { Wet } \\
\text { land }\end{array}$} & \multirow[b]{2}{*}{ Others } & \\
\hline & Awal & Doyam & Seem & Chahar & Total & & & & \\
\hline tal & 10 & 272 & 24 & 11 & 1030 & 147679 & 518 & 208073 & 357300 \\
\hline$\%$ & 0.00 & 0.08 & 0.06 & 0.00 & 0.29 & 41.33 & 0.14 & 58.23 & 100 \\
\hline
\end{tabular}

Source: ForestAction Nepal, 2009 (Compiled from Central Bureau of Statistics, 1993).

Annexes 3: Major products in Mustang by their quantities

\begin{tabular}{|c|c|c|c|c|c|c|c|c|}
\hline & \multicolumn{5}{|c|}{ Food Grains (MT) } & & & \\
\hline & Maize & Wheat & Barley & Potato & total & Pulses & $\begin{array}{c}\text { Animal }_{\text {products }}^{7} \\
\text { prothers }^{8}\end{array}$ & Oth. $^{8}$ \\
\hline Qty & 1240 & 644 & 2737 & 5206 & 995 & 1551 & 2131 \\
\hline$\%$ & 11.2 & 23.8 & 12.4 & 52.6 & 100.0 & & & \\
\hline
\end{tabular}

Source: ForestAction Nepal, 2009 (Synthesized from Agri-Business Promotion and Marketing Development Directories, 2008; District Profile, 2007/08; Agri-Bussiness Promotion and Statistics Division, 2001; and Department of Land Revenue, HMG/N, 2002). 